\title{
Arsenic microdistribution and speciation in toenail clippings of children living in a historic gold mining area
}

\author{
Dora C. Pearce a,*, Kim Dowling a , Andrea R. Gerson ${ }^{\mathrm{b}}$, Malcolm R. Sim ${ }^{\mathrm{c}}$, Stephen R. Sutton ${ }^{\mathrm{d}, \mathrm{e}}$, \\ Matthew Newville ${ }^{\mathrm{d}}$, Robert Russell ${ }^{\mathrm{f}}$, Gordon McOrist ${ }^{\mathrm{g}}$
}

\footnotetext{
a School of Science and Engineering, University of Ballarat, Mt Helen Campus, University Drive, Mt Helen, Victoria 3350, Australia

${ }^{\mathrm{b}}$ Applied Centre for Structural and Synchrotron Studies (ACeSSS), Division of Information Technology, Engineering and the Environment, University of South Australia, Mawson Lakes, South Australia 5095, Australia

${ }^{\mathrm{c}}$ Monash Centre for Occupational \& Environmental Health (MonCOEH), Department of Epidemiology E' Preventive Medicine, Faculty of Medicine, Nursing and Health Sciences, Monash University, The Alfred Hospital, Commercial Road, Melbourne, Victoria 3004, Australia

' Center for Advanced Radiation Sources, University of Chicago, 9700 South Cass Avenue, Building 434A, Argonne, IL 60439, USA

e Department of Geophysical Sciences, University of Chicago, 9700 South Cass Avenue, Building 434A, Argonne, IL 60439, USA

${ }^{\mathrm{f}}$ Australian Nuclear Science and Technology Organisation (ANSTO) Institute for Environmental Research, PMB 1 Menai NSW 2234, Australia

${ }^{g}$ ANSTO Minerals, PMB 1 Menai NSW 2234, Australia
}

\section{Introduction}

Arsenic is commonly associated with gold mineralisation, and elevated arsenic concentrations have been observed in mine waste, soils, and surface and groundwaters in areas of historic gold mining

\footnotetext{
* Corresponding author. School of Science and Engineering, University of Ballarat, PO Box 663, Ballarat, Victoria 3353, Australia. Tel.: +61 35327 9242; fax: +61 35327 9240.

E-mail address: d.pearce@ballarat.edu.au (D.C. Pearce).
}

activity in Australia (DMID, 1991; Smith et al., 2003; Sultan, 2007). Residential development has occurred around these areas, and mine waste material has occasionally been used for fill (enHealth Council, 1999). Adverse health effects associated with chronic exposure to arsenic-contaminated drinking water are well established (Centeno et al., 2007). Although bacteriologically safe, water extracted from subsurface alluvial aquifers may be contaminated through the release of sorbed arsenic, which is linked to the reductive dissolution of iron oxyhydroxide present in sedimentary deposits (Nickson et al., 2000; McArthur et al., 2001). Similarly, in some soils in rural Victoria, Australia, arsenic mobility is influenced by weathering of sulphide-containing minerals, such as arsenopyrite, producing iron oxide-hydroxides which 
serve as either a source or a sink for arsenic, depending on soil chemistry (Sultan and Dowling, 2006a) and seasonal fluctuations (Sultan and Dowling, 2006b).

Toenail clippings provide a validated biological matrix for investigating chronic exposure to arsenic in drinking water when exogenous contamination is removed (Slotnick and Nriagu, 2006). Evidence of exposure to arsenic in soil has also been demonstrated using urine and toenail clippings to investigate biomarkers, although residual external contamination on toenail clippings may have contributed to the elevated arsenic concentrations observed (Hinwood et al., 2003, 2004). Importantly, arsenic concentrations in nail clippings from children were significantly higher than adults in high soil arsenic areas (Hinwood et al., 2003; Wickre et al., 2004). Elemental concentrations in hair may be indicative of exposure patterns (Hopps, 1977; Koons and Peters, 1994), and tend to be correlated with those in nails (Rodushkin and Axelsson 2000), since keratins in hair and nails are similar (Kitahara and Ogawa, 1991). Synchrotron-based X-ray fluorescence (XRF) enables quantitative mapping of the microdistribution of elements in biologic samples (Fahrni, 2007), and may therefore be applied to explore exposure patterns in nails.

Determination of arsenic speciation is essential to fully understand arsenic transformation, fate of arsenicals and their toxicity in human tissues. Trivalent arsenicals are more toxic than pentavalent species (Kligerman et al., 2005), and monomethylarsonous acid (MMA ${ }^{\mathrm{III}}$ ) is possibly more toxic than arsenite (Petrick et al., 2000). Biomarkers in urine, typically used to investigate arsenic speciation (Concha et al., 1998; Kurttio et al., 1998; Mandal et al., 2001; Alauddin et al., 2003; Hinwood et al., 2004), are indicative of short term exposures, with almost $50 \%$ of an oral dose of inorganic arsenic being excreted in urine within four days (Buchet et al., 1981). Although indicative of chronic exposures, speciation studies dependent on the extraction of arsenicals from hair and nails may be subject to extraction inefficiencies and species instability (Mandal et al., 2004; Raab and Feldmann, 2005; Button et al., 2009). External contamination of nail samples (Hinwood et al., 2003) may also interfere with such indirect speciation studies. Synchrotron-based techniques, such as X-ray absorption spectroscopy (XAS), enable determination of the oxidation state of specific elements in situ in biologic samples with minimal preparation (Smith et al., 2005). In particular, X-ray absorption nearedge structure (XANES) measurements enable differentiation between trivalent and pentavalent arsenic, and inorganic and organic (methylated) arsenic compounds (Smith et al., 2005).

In association with a cross-sectional survey of arsenic concentrations in children's toenail clippings and residential soils in an area of historical gold mining in rural Victoria, Australia, we aimed to investigate: (i) the microdistribution and speciation of arsenic in children's toenail clippings; (ii) the potential for direct diffusion of arsenic from mine waste into toenail clippings; and (iii) the presence of residual surface contamination on cleaned clippings. We applied synchrotron-based XRF and XANES to investigate the microdistribution and speciation, respectively, of arsenic in situ in thin sections of two toenail clippings, thus enabling an exploration of exposure patterns while reducing the risk of modifying the speciation of arsenic present. The extent of the contribution of exogenous arsenic to biomarker concentrations in toenail clippings is uncertain. We used XANES to compare arsenic speciation in thin sections of three clippings from a single participant, either untreated or incubated in dry or wet mine waste, to explore the ability of this technique to differentiate between systemically absorbed and exogenous arsenic. We also applied the depth profiling technique, Secondary Ion Mass Spectrometry (SIMS), to whole clippings to investigate surface arsenic contamination.

\section{Materials and methods}

Approvals for this research were granted by the Human Research Ethics Committee of the University of Ballarat, the Department of
Education and Training Victoria, and principals of the two participating primary schools (responsible for the first 7 years of schooling). Parental informed, written consent for each child participant was obtained prior to study commencement.

\subsection{Sample collection and preparation}

Demographic data and information about children's diet and play activity were collected by questionnaire. Toenail clipping samples $(n=29)$ from children aged 5-13 years (males, 41\%), were collected during the 2006 school year, and stored at room temperature. Visible nail polish was removed with acetone. Clippings were cleaned by sonication for $15 \mathrm{~min}$ in $10 \mathrm{ml}$ of deionised water, rinsed twice, and this procedure repeated prior to collection by vacuum filtration, removal of any insoluble debris, and drying in an incubator at $10{ }^{\circ} \mathrm{C}$ (Karagas et al., 2000). Where two large clipping samples were provided they were investigated separately $(n=2)$. A single clipping was retained from each of 10 sufficiently large samples, weight range 0.02 to $0.15 \mathrm{~g}$, for further investigations. Of three clippings retained from a single sample, one was retained as a control, one was incubated in $0.5 \mathrm{~g}$ dry mine waste, another in a slurry of $0.5 \mathrm{~g}$ (dry weight) and deionised water, for a week in sealed sterile containers at $26{ }^{\circ} \mathrm{C}$ to simulate normal skin temperature in children's toes (Mork et al., 2002 ). Mine waste (arsenic concentration $\approx 400 \mathrm{mg} / \mathrm{kg}$ ) was sieved to $<106 \mu \mathrm{m}$ to maximise surface contact and simulate particles likely to be retained under toenails (Rahman et al., 1994).

Composite soil samples, derived from five strategic locations using a $10 \mathrm{~cm}$ bore auger, were obtained from each residence $(n=22)$ where the children frequently played. Soil was mixed, oven dried at $\approx 40{ }^{\circ} \mathrm{C}$ for 3 days, crushed using a pestle and mortar if necessary, and sieved to $<2 \mathrm{~mm}$. Duplicate samples $(n=6)$ were analysed to assess completeness of mixing.

\subsection{Arsenic quantification by INAA}

Arsenic in clippings and soils was quantified using Instrumental Neutron Activation Analysis (INAA) at the Australian Nuclear Science and Technology Organisation (ANSTO). Clipping samples, weighing $5.4 \mathrm{mg}$ to $150.8 \mathrm{mg}$ (median $27.8 \mathrm{mg}$ ), were irradiated for $5 \mathrm{~min}$ with neutrons in the X-176 irradiation facility of HIFAR. Arsenic standards were prepared from $1000 \mathrm{ppm}$ As ICP standard solutions, and duplicate or triplicate samples of National Bureau of Standards (NBS) Standard Reference Material 1571 Orchard Leaves were included with the two batches of clippings. Following decay periods varying from 6 to $30 \mathrm{~h}$, clippings were counted for $60 \mathrm{~min}$ on a 20\% Ortec HPGe detector, and arsenic concentrations calculated. Around $0.1 \mathrm{~g}$ of soil sample was analysed in parallel with arsenic standards prepared from similar amounts of International Atomic Energy Agency (IAEA) Soil-5 and IAEA SL-1. Soil samples were irradiated for $1 \mathrm{~min}$, and following decay periods varying from 20 to $30 \mathrm{~h}$, soils were counted for $30 \mathrm{~min}$ to enable arsenic concentrations to be calculated.

\subsection{Toenail clipping thin sectioning}

Thin sections were prepared by bisecting the clippings with a stainless steel scalpel blade, and fixing the newly cut surfaces end on in Teflon moulds, orientated such that the curved surfaces of the clipping portions were parallel. Resin (Araldite K-3600 2-part epoxy resin, mixed $3: 1$ ) in moulds was set overnight at $\approx 30^{\circ} \mathrm{C}$. Resin blocks were ground on a diamond grinder and polished (Kent MK 2A, Engis Ltd., Maidstone, England). Polished surfaces were fixed to silica slides with ThreeBond UV Curing resin (cement) and cured with UV light for $20 \mathrm{~min}$, sections cut on a petrographic thin section saw-grinder (PSG 200-V, Australian Petrographics, Queanbeyan, NSW, Australia), and lapped (Kemet KPL 300 Precision Lapping Machine, Engis Australia Pty. Ltd., Marayong, 
NSW, Australia) to a thickness of $50 \mu \mathrm{m}$ initially, but due to the fragility of the thin sections, the remaining samples were lapped to $100 \mu \mathrm{m}$. Upper surfaces were polished, and slides cleaned by sonication for $1 \mathrm{~min}$ in deionised water. Thin sections of the control and incubated clippings were prepared similarly, but fragility of incubated clippings caused uncertainty in the final orientation.

\subsection{XRF and XANES spectroscopy}

The X-ray microprobe at GeoSoilEnviroCARS (Sector 13), Advanced Photon Source (APS), Argonne National Laboratory, U.S.A., was used for the XRF and XANES analyses (Sutton et al., 2002). XRF line scans were measured to identify suitably non-fragmented toenail clipping thin sections with detectable arsenic (detector-air path length of $35 \mathrm{~mm}$, beam size of $3 \pm 1 \mu \mathrm{m}, 5 \mathrm{~s}$ per spot, step size of $5 \mu \mathrm{m}$ and incident X-ray energy of $13.0 \mathrm{keV}$ ). Thin sections from two participants, designated TS1 and TS2, were further investigated during the $48 \mathrm{~h}$ beamtime allocation. For XRF mapping, the X-ray beam size was increased to $10 \times 10 \mu \mathrm{m}$, counting for $2 \mathrm{~s}$ per spot with step size of $10 \mu \mathrm{m}$. On the basis of XRF mapping, spot locations of interest were selected to investigate arsenic speciation and estimate arsenic concentration. XANES spectra were collected in fluorescence mode using a Vortex EX silicon drift energy dispersive detector (SIl NanoTechnology Inc.). The arsenic signal was boosted by positioning aluminum foil over the detector to suppress signals from lower energy fluorescence lines, thereby avoiding detector saturation when the detector-sample distance was minimised and the associated solid angle increased. Arsenite $\left(\mathrm{As}_{2}^{\mathrm{III}}{ }_{2} \mathrm{O}_{3}\right)$, arsenate $\left(\mathrm{As}_{2}{ }_{2} \mathrm{O}_{5}\right)$ and realgar $\left(A s^{I I} \mathrm{~S}\right)$ standards were run as solids in transmission mode. A similar procedure was followed for the investigation of arsenic diffusion into incubated toenail clippings. Standards were used as relative energy calibrants between sessions, and the energy offset of $-3 \mathrm{eV}$ obtained in the second session was used to correct XANES spectra from the control and incubated clippings for the energy calibration difference.

XRF maps were derived using DataViewer Version 2.03 (Newville, 2006). Where multiple XANES spectra were available from individual spot locations, they were merged with background subtraction and normalisation carried out using Athena 0.8.050 software (Ravel, 2001-2006), and absorption edge peak energies extracted. One iteration of interpolative smoothing was applied to spectra from TS2 and the control clipping, two iterations to the clipping incubated in dry mine waste. Spectra from spots on the clipping incubated in wet mine waste required no smoothing, likely due to a stronger signal associated with higher arsenic concentration.

The linear combination fitting procedure of Athena was used to compare arsenic speciation at TS1 spots 1 and 9 with species at other spots on TS1, and spots on TS2, the control and incubated clippings. Fits were performed using normalised $\mu(E)$ spectra over the data range -30 to $+60 \mathrm{eV}$ of the default $E_{0}$ [first peak of the first derivative of $\mu(E)$ ], with standard weights constrained to between 0 and 1 , and summing to 1 (Ravel, 2007). Goodness of fit was assessed by the reduced chi-square statistic. Additional rescaling of XANES spectra for energies between 11,860 and 11,890 eV was undertaken using Microsoft Office XP Excel for Windows (Microsoft Corporation, Redmond, WA) to facilitate comparisons between arsenic speciation at spot locations and standards.

For TS1 and TS2, absolute element concentrations for individual pixels in the maps and spot XRF analyses were determined from net fluorescence peak areas extracted from the full XRF spectra using a Gaussian peak fitting feature of MCA-IDL Multichannel Analyzer Program (Rivers, 1997). The net peak areas were converted to elemental masses (mass/area) using comparable XRF measurements on SRM thin film standards 1832/1833 (NIST, USA), and using the NRLXRF - Cosmic program \#DOD-00065, US Naval Research Laboratory (Birks et al., 1977) to extrapolate elemental sensitivities to elements not present in the SRMs and correct for sensitivity differences between the thin films and the toenail clipping thin sections. Concentrations (element mass fractions by weight) were computed by dividing the elemental masses by specimen thicknesses, the latter estimated by multiplying the assumed nail density of $1.2 \mathrm{~g} / \mathrm{cm}^{3}$ by the optically-determined thicknesses of 95 and $110 \mu \mathrm{m}$ for TS1 and TS2, respectively.

\subsection{SIMS depth profiling}

SIMS instrumentation (ims-5f, Cameca, France) was used for depth profiling of whole clipping surfaces at the ANSTO Institute for Environmental Research, Australia. Depth of analysis was not calibrated, since the purpose was to assess the presence of arsenic as a surface contaminant After sputter-coating with gold to approximately $20 \mathrm{~nm}$ to alleviate charging, depth profiles were collected using caesium ions $\left(\mathrm{Cs}^{+}\right)$as the primary beam. The sputtered secondary ions collected were negative ions of carbon, oxygen and arsenic, and signals were normalised to the matrix element, carbon.

\subsection{Statistical analysis}

For clipping samples with arsenic concentration below detection limits (DL), half the DL for that sample was assigned. Where two large clipping samples were provided and investigated separately $(n=2)$, arsenic concentrations above the DL were available in one sample only and used in subsequent analyses. The highest of duplicate soil arsenic concentrations was used. Correlations between natural logarithmic transforms of toenail clipping and soil arsenic concentrations, and clipping arsenic concentration and weight, were assessed using Pearson's correlation coefficient. Agreement between duplicate soil samples was assessed using the Exact Wilcoxon Signed Rank test for matched pairs, and batch results for NBS 1571 orchard leaves were compared using the Exact Wilcoxon Rank-Sum test. A 2-tailed significance level of 0.05 was used in statistical analyses, performed using SPSS Version 12.0.1 for Windows.

\section{Results}

\subsection{Arsenic concentrations in toenail clippings and soil samples}

Toenail arsenic concentrations ranged from 0.15 to $2.1 \mu \mathrm{g} / \mathrm{g}$ (geometric mean, $0.49 \mu \mathrm{g} / \mathrm{g}$ ). Natural logarithmic transformed clipping weights (range $5.4 \mathrm{mg}$ to $151 \mathrm{mg}$ ) and arsenic concentrations were not significantly correlated (Pearson's $r=-0.174, P=0.367$ ). Arsenic concentrations determined for the NBS 1571 orchard leaves ranged between $8.1 \pm 0.3 \mu \mathrm{g} / \mathrm{g}$ and $11.6 \pm 0.3 \mu \mathrm{g} / \mathrm{g}$, within the certified range of $10 \pm 2 \mu \mathrm{g} / \mathrm{g}$, and with no significant difference between batches (medians $8.8 \mu \mathrm{g} / \mathrm{g}$ and $11.2 \mu / \mathrm{g} ; P=0.20$ ).

Household soil arsenic concentrations were between $3.3 \mu \mathrm{g} / \mathrm{g}$ and $130 \mu \mathrm{g} / \mathrm{g}$ (geometric mean, $11.5 \mu \mathrm{g} / \mathrm{g}$ ). Quality control samples for soil were also within the certified range of values: IAEA Soil-5 arsenic concentration $90 \pm 13 \mu \mathrm{g} / \mathrm{g}$ [CRM $93.9 \pm 7.5 \mu \mathrm{g} / \mathrm{g}$ ] and IAEA SL-1 (lake sediment) $29 \pm 4 \mu \mathrm{g} / \mathrm{g}$ [CRM $27.5 \pm 3.0 \mu \mathrm{g} / \mathrm{g}$ ]. Replicate soil samples ( $n=6$; median percent difference $20 \%$ ) did not differ significantly $(P=1.00)$. A moderate positive correlation between the transformed clipping and soil arsenic concentrations was observed (Pearson's $r=0.42, P=0.023$ ) when household soil arsenic concentrations for each participant were treated as independent.

\subsection{Microdistribution of arsenic and other elements in children's toenail clipping thin sections}

The two toenail clipping thin sections, TS1 and TS2, used to investigate arsenic microdistribution and speciation were selected on the basis of the As $K_{\alpha}$ fluorescence peak detected at around $10.54 \mathrm{keV}$. Since arsenic has an affinity for the sulphydryl groups of keratinic matrices such as nail (Palmeri et al., 2000; Beane Freeman et al., 2004), sulphur maps of TS1 and TS2 (Fig. 1, Ai and $\mathrm{Bi}$, respectively) were used to delineate the corresponding arsenic maps (Fig. 1, Aii and Bii, respectively). However, 
the microdistribution of arsenic and other elements may not correspond exactly with these outlines due to the $45^{\circ}$ incidence angle of the incoming $\mathrm{X}$-rays, difference in energies of $\mathrm{K}$ fluorescence $\mathrm{X}$-rays between elements, and the variable and unknown geometry of the nail structure with section depth.

Arsenic was detected at two sites in the upper margin of TS1, indicated by red double arrows (Fig. 1Aii), with arsenic concentrations of $2.2 \mu \mathrm{g} / \mathrm{g}$ and $13.3 \mu \mathrm{g} / \mathrm{g}$ (Table 1 ) at spots 2 and 9 , respectively (Fig. 2A). Thin section TS2 reflects a shorter growth period, but also displays some evidence of arsenic deposition in the upper margin (Fig. 1Bii). Arsenic concentrations of $1.5,0.8$ and $0.1 \mu \mathrm{g} / \mathrm{g}$ at spots 9,12 and 11, respectively (Fig. 2B) indicate lower arsenic concentrations at the surface and interior of the clipping. Arsenic extends almost halfway along the lower margins from the distal free edge, with spot concentrations in TS1 ranging between 0.1 and $6.8 \mu \mathrm{g} / \mathrm{g}$, and up to $7.8 \mu \mathrm{g} / \mathrm{g}$ in TS2. Spot arsenic concentrations between upper and lower margins were $\leq 0.7 \mu \mathrm{g} / \mathrm{g}$. The microdistributions and concentration ranges of calcium, copper, and zinc differed from one another, and from arsenic, in TS1 and TS2 (Fig. 3A and B, respectively). Iron was concentrated at the tip of the distal free edges of TS1 and TS2, and although not detected along the lower margin of TS1, iron and arsenic coincided in the upper margin.

\subsection{Speciation of arsenic}

Spots on TS1 and TS2 investigated using XANES, and where arsenic concentrations were estimated, are shown in Fig. 2A and B, respectively. Arsenic is clearly present as two distinct species, with absorption edge peak energies of $11,870.5-11,871.5 \mathrm{eV}$ corresponding to a lower
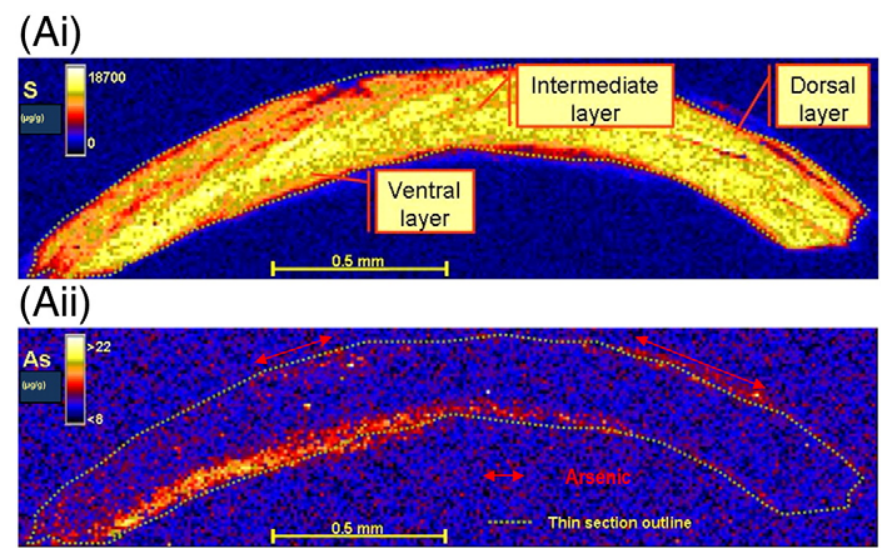

(Bi)

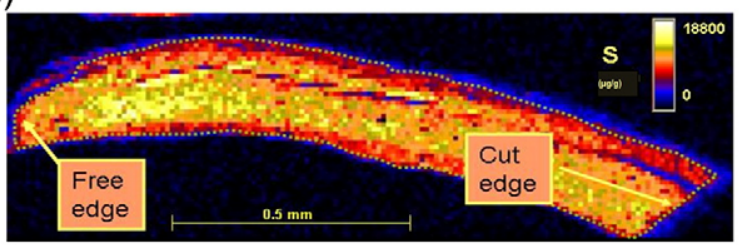

(Bii)

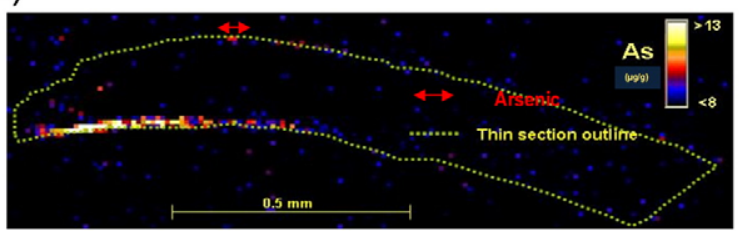

Fig. 1. XRF maps of toenail clipping thin sections showing dorsal, ventral and intermediate nail layers, free distal and recently cut edges of clipping. Figures Ai and Aii show sulphur and arsenic maps, respectively for toenail clipping thin section TS1. Figures Bi and Bii show sulphur and arsenic maps, respectively, for toenail clipping thin section TS2. Color bars indicate concentration ranges $(\mu \mathrm{g} / \mathrm{g})$ oxidation state arsenic species, and 11,876.0-11,876.5 eV corresponding to a higher oxidation state arsenic species (Table 1 , Fig. 4). XANES spectra of TS1 spots 1 and 6 show the less oxidised arsenic species, possibly with significant sulphur bonding as indicated by maxima between those of realgar and arsenite $(11,870 \mathrm{eV}$ and $11,872 \mathrm{eV}$, respectively). Spectra from TS2 spots $1,4,9$, and 12 similarly indicate that the dominant form of arsenic is in the lower oxidation state. The more oxidised arsenic species was dominant in spectra of TS1 spots 2 and 9, with an absorption edge peak energy (white line energy) greater than arsenate $(11,875 \mathrm{eV})$. Although the spectrum for TS2 spot 8 is noisy, it is suggestive of the more oxidised species. Linear combination fitting using the low and high oxidation state species, TS1 spots 1 and 9, respectively, as standards suggests mixed speciation for TS1 spot 2 and TS2 spots 4, 8 and 12 (Table 2). Hence, the lower oxidation state arsenic species was detected in both the lower and upper margins of TS1 and TS2, while the more oxidised species was detected in the upper margin of TS1 and both margins of TS2.

\subsection{Potential for direct diffusion of arsenic into toenail clippings}

While the control and incubated clippings were obtained from a single participant, it is likely they were collected from different toes, and a comparison of arsenic distribution and concentration between individual clippings was beyond the scope of this study. XRF mapping was only used to select spots with high arsenic for XANES analysis, due to the uncertainty in orientation of thin sections from incubated clippings, and severe fragmentation of the clipping incubated in wet mine waste. Arsenic $K_{\alpha}$ fluorescence was detected in two of six XRF spectra collected from the control clipping; four of six spectra from the clipping incubated in dry mine waste; and strong arsenic signals were detected at all nine spot locations investigated from the clipping incubated in wet mine waste, with some $K_{\beta}$ fluorescence also evident at around $11.73 \mathrm{keV}$ (Fig. 5A, B, and C). Linear combination fitting demonstrated that arsenic in the lower oxidation state was the dominant species at two spots investigated on the control clipping (Table 2). On the thin section of the clipping incubated in dry mine waste, two spots corresponded primarily to the lower oxidation state species, one to the higher oxidation species, with mixed speciation evident at the fourth spot. All three spots investigated on the thin section of the clipping incubated in wet mine waste corresponded to the higher oxidation state arsenic species.

\subsection{SIMS depth profiling}

Dorsal surfaces of the toenail clippings investigated were smoother than the ridged ventral surfaces, and therefore more suited to SIMS analysis. An initial arsenic signal prior to stabilisation of the oxygen signal is likely due to ease of ionisation and preferential sputtering of arsenic in this matrix, but may represent surface contamination (Fig. 6). The arsenic signal varied in intensity between replicate analyses at different locations on a single clipping (Fig. 6Ai and ii). Deviation of the arsenic signal with depth from those of carbon and oxygen is evident in clippings from samples with total arsenic concentrations of $0.77 \mu \mathrm{g} / \mathrm{g}$ and $0.23 \mu \mathrm{g} / \mathrm{g}$ (Fig. 6A and B, respectively), and suggestive of arsenic peaks within the nail matrix. Arsenic was also evident within a clipping from a sample with $0.73 \mu \mathrm{g} / \mathrm{g}$ total arsenic, but less evident in a clipping $(0.29 \mu \mathrm{g} / \mathrm{g})$ after washing with acetone to remove nail polish (not shown).

\section{Discussion}

Synchrotron-based XRF mapping of clipping thin sections revealed arsenic in discrete layers, and although we did not investigate nail structure, the patterns observed in thin sections TS1 and TS2 are consistent with structural differences between the three layers comprising the nail plate (Farren et al., 2004). The intermediate nail 
Table 1

Results of X-ray absorption near-edge spectroscopy at designated spots on toenail clipping thin sections TS1 and TS2 indicating likely nail layers and arsenic speciation.

\begin{tabular}{|c|c|c|c|c|}
\hline Likely nail layer & Spot number & $\begin{array}{l}\text { Spot arsenic concentration } \\
(\mu \mathrm{g} / \mathrm{g})^{\mathrm{a}}\end{array}$ & Dominant arsenic speciation & $\begin{array}{l}\text { Absorption edge peak energy } \\
(\mathrm{eV})\end{array}$ \\
\hline \multicolumn{5}{|l|}{ TS1 } \\
\hline \multirow[t]{4}{*}{ Ventral } & 1 & 6.8 & 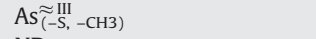 & $11,871.0$ \\
\hline & 4 & 0.1 & ND & ND \\
\hline & 6 & 4.5 & $\mathrm{As}_{(-\mathrm{S},-\mathrm{CH} 3)}$ & $11,870.5$ \\
\hline & 7 & 3.0 & ND & ND \\
\hline \multirow[t]{2}{*}{ Dorsal } & 2 & 2.2 & $\mathrm{As} \approx \mathrm{V}_{(-\mathrm{O})}$ & $11,876.0$ \\
\hline & 9 & 13.3 & $\mathrm{As}_{(-\mathrm{O})} \mathrm{V}$ & $11,876.5$ \\
\hline \multirow[t]{4}{*}{ Intermediate } & 3 & 0.2 & ND & ND \\
\hline & 5 & 0.7 & ND & ND \\
\hline & 8 & 0.7 & ND & ND \\
\hline & 10 & 0.1 & ND & ND \\
\hline \multicolumn{5}{|l|}{ TS2 } \\
\hline \multirow[t]{8}{*}{ Ventral } & 1 & 6.5 & $\mathrm{As}_{(-\mathrm{S},-\mathrm{CH} 3)} \approx \mathrm{II}$ & $11,871.0$ \\
\hline & 2 & 7.8 & ND & ND \\
\hline & 3 & 4.2 & ND & ND \\
\hline & 4 & 2.2 & $\mathrm{As}_{(-\mathrm{S},-\mathrm{CH} 3)}^{\approx \mathrm{III}}$ & $11,871.0$ \\
\hline & 5 & $<0.1$ & ND & ND \\
\hline & 6 & 1.7 & ND & ND \\
\hline & 7 & 0.2 & ND & ND \\
\hline & $8^{\mathrm{b}}$ & 0.2 & $\mathrm{As} \approx \overline{(-0)}$ & $11,876.5$ \\
\hline \multirow[t]{2}{*}{ Dorsal } & 9 & 1.5 & $\mathrm{As}_{(-\mathrm{S},-\mathrm{CH} 3)} \approx$ & $11,871.5$ \\
\hline & 12 & 0.8 & $\mathrm{As}_{(-\mathrm{S},-\mathrm{CH} 3)}$ & $11,871.5$ \\
\hline \multirow[t]{2}{*}{ Intermediate } & 10 & 0.1 & ND & ND \\
\hline & 11 & 0.1 & ND & ND \\
\hline \multicolumn{5}{|c|}{ Model compounds } \\
\hline Realgar & - & - & - & 11,870 \\
\hline Arsenite & - & - & - & 11,872 \\
\hline Arsenate & - & - & - & 11,875 \\
\hline
\end{tabular}

Abbreviations: As $\approx$ III $-\mathrm{CH} 3)$, low oxidation state (approximately trivalent) arsenic bound to sulphur and methyl groups; As $\approx \mathrm{v}$, higher oxidation state (approximately pentavalent) arsenic species bound to oxygen; eV, electron volts; ND, not determined.

a Uncertainties in As concentration are $\sim 0.1 \mu \mathrm{g} / \mathrm{g}$.

b Speciation suggestive only due to low arsenic concentration and noise in XANES spectra.

plate is richer in stable disulphide bonds than the dorsal layer, which has a higher concentration of free sulphydryl groups, and like the ventral layer, is less structured (Garson et al., 2000). This disparity in sulphur bonding has implications for arsenic incorporation into nail keratin, since arsenite binds strongly to free sulphydryl groups, more so than arsenate (Kitchin et al., 2003). SIMS analysis confirmed an arsenic peak just below clipping surfaces and XRF mapping showed little arsenic incorporation in the intermediate layer. Consistent with our findings, Rodushkin and Axelsson (2003) found arsenic to be most concentrated in the uppermost $100 \mu \mathrm{m}$ of a fingernail, about a quarter of fingernail thickness. Rigorous cleaning may result in some leaching of arsenic from clippings (Button et al., 2009), and the lower arsenic

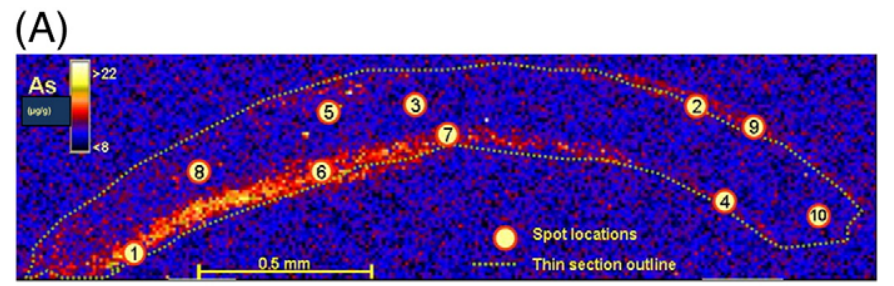

(B)

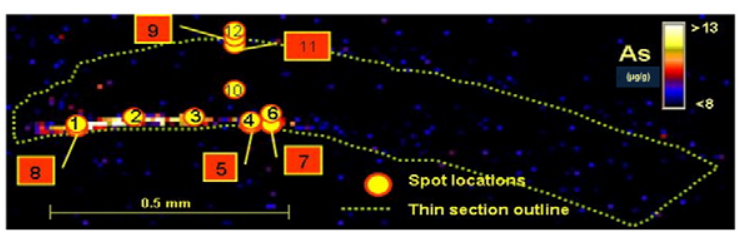

Fig. 2. Spot locations where XANES analyses, and/or concentration estimation by spot XRF analysis, were undertaken are shown for thin sections TS1 (A) and TS2 (B). concentrations at the periphery of TS2 compared with the immediately adjacent spot locations within the dorsal and ventral layers is suggestive that any surface contamination was removed and that some leaching occurred during cleaning.

The irregularity and heterogeneity of arsenic concentration along the nail growth axis in dorsal layers of TS1 and TS2 are consistent with results obtained by Gault et al. (2008) from Proton Induced X-ray Emission (PIXE) analysis applied to a whole fingernail from an individual exposed to arsenic in groundwater. Gault et al. (2008) concluded that the patterning of arsenic was indicative of episodic arsenic intake over the growth of the nail. This is likely, since elements accumulated during the nail's growth period are retained, thus providing information about exposure patterns (Hopps, 1977; Takagi et al., 1988; Koons and Peters, 1994; Sukumar, 2006). Assuming an average toenail growth rate for children of around $1 \mathrm{~mm}$ per month (Le Gros Clark and Buxton, 1938; Bean, 1953), TS1 reflects around $21 /$ 2 months growth, and TS2 around $11 / 2$ months growth. While the timing of exposures cannot be precisely estimated due to variation in growth rates of toenails within and between individual children, it is likely these exposures occurred several months prior during Australia's warm season, when outdoor play is customary. Arsenic may derive from dietary as well as environmental sources, particularly seafood (Slotnick et al., 2007). However, TS1 and TS2 were sourced from participants who were unlikely to be exposed to arsenic in seafood or water, but potentially exposed to soil arsenic.

Our finding that arsenic and iron were incorporated into the nail at corresponding locations is also consistent with results obtained from PIXE analysis by Gault et al. (2008) which showed that the highest arsenic and iron values occurred together. Moreover, XRF maps of TS1 revealed that arsenic, copper and iron are incorporated into the dorsal and ventral layer, while zinc is distributed throughout. These distribution 
(A)
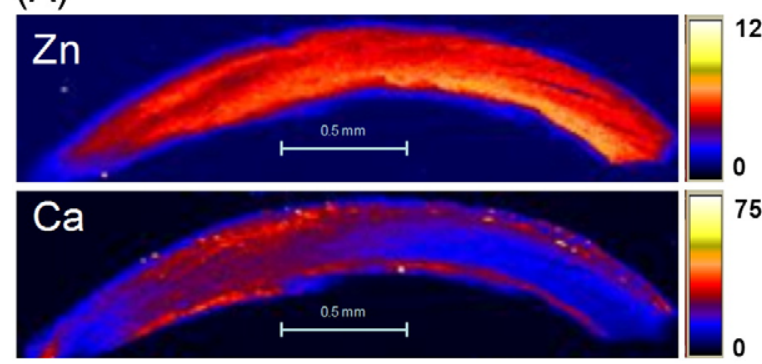

(B)
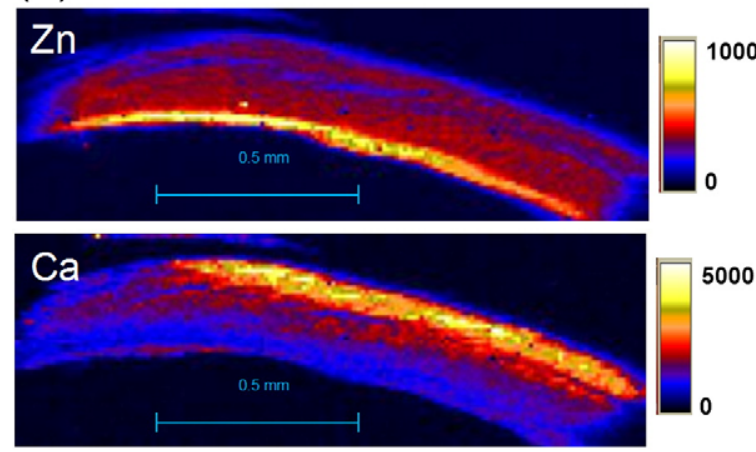
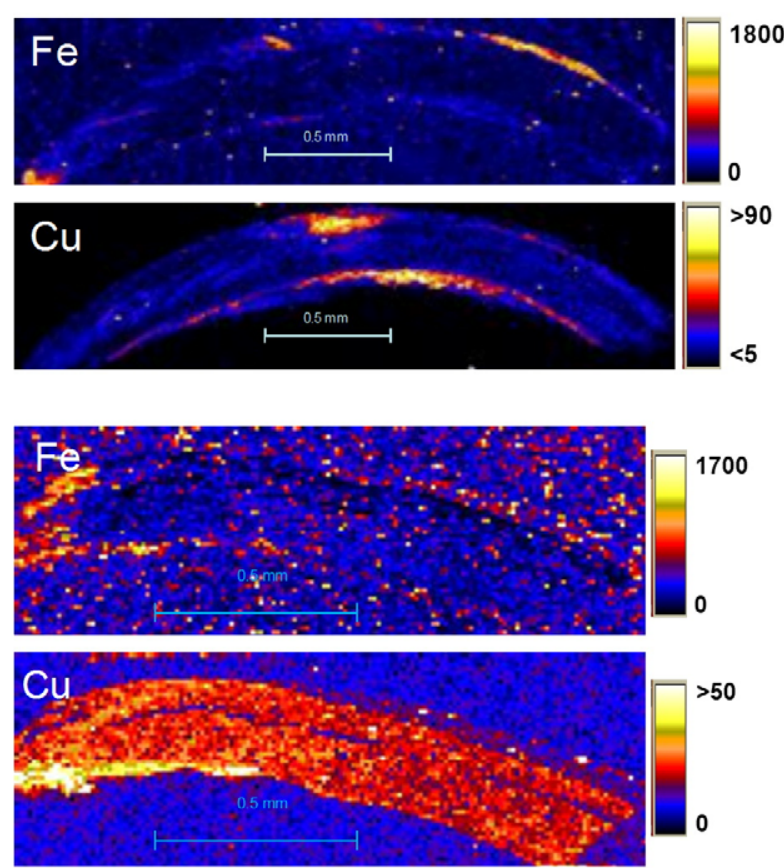

Fig. 3. XRF maps of TS1 (A) and TS2 (B) showing differing microdistributions of $\mathrm{Zn}, \mathrm{Ca}$, Fe and Cu. Color bars indicate concentration ranges ( $\mu \mathrm{g} / \mathrm{g}$ ).

patterns are also consistent with those identified by Rodushkin and Axelsson (2003) using laser ablation, showing that copper was concentrated in the uppermost layer, while zinc was more uniformly

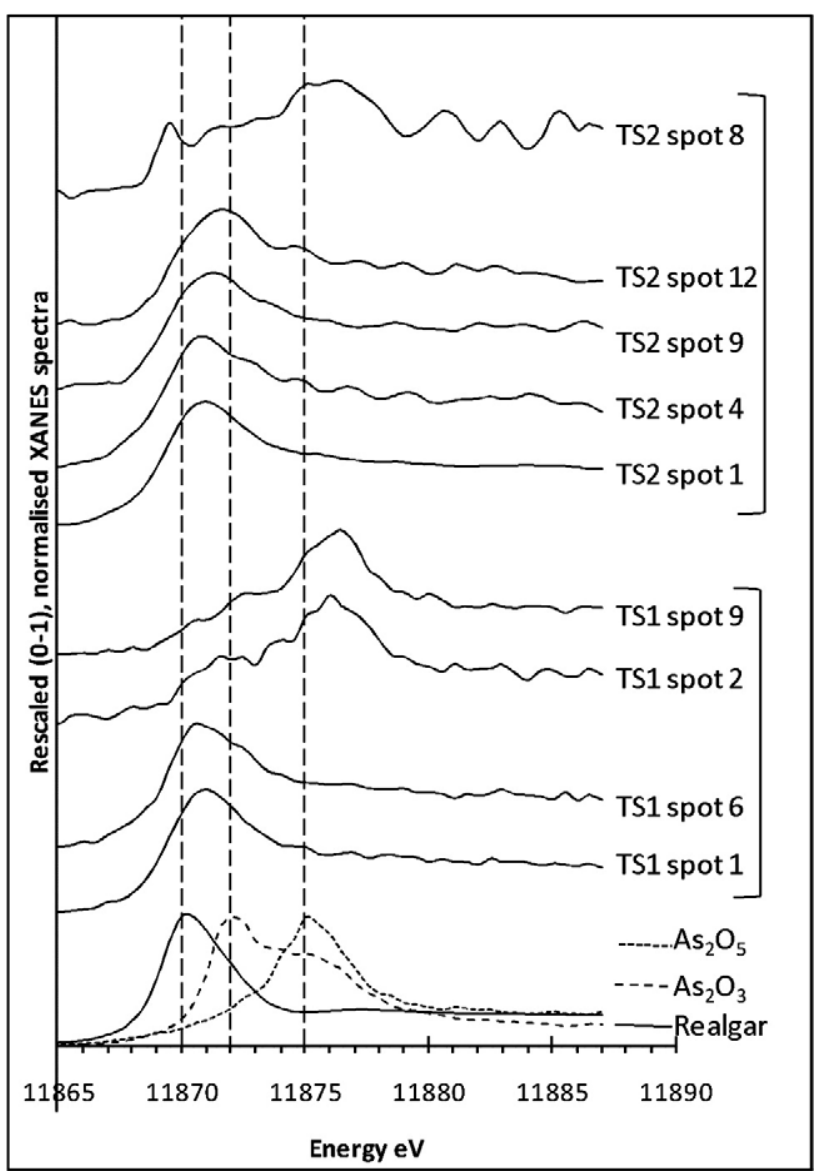

Fig. 4. Normalised XANES spectra of standards $\mathrm{As}_{2} \mathrm{O}_{3}, \mathrm{As}_{2} \mathrm{O}_{5}$, and realgar, and from specified spot locations on TS1 and TS2, rescaled to range from 0 to 1 and offset for comparison. distributed. It is possible that iron concentrated at the free edges of TS1 and TS2 is due to contamination by nail clippers (Rodushkin and Axelsson, 2003), however, any redistribution of elements occurring during thin section preparation is likely to be minimal.

The difference in distribution of arsenic between the dorsal and ventral layers may be expected, since nails have a plentiful blood supply to both the nail root and nail bed, each of which contributes to nail growth (Samman, 1978), and the formation of the ventral layer is

Table 2

Linear combination fits between -30 and $+60 \mathrm{eV}$ for XANES spectra at spot locations on thin sections of control and incubated toenail clippings, using the low and high oxidation state arsenic species identified in TS1 as standards.

\begin{tabular}{llcl}
\hline Spot & $\begin{array}{l}\text { Low oxidation state arsenic } \\
\text { species [TS1 spot 1] \% }\end{array}$ & $\begin{array}{l}\text { High oxidation state arsenic } \\
\text { species [TS1 spot 9] \% }\end{array}$ & $\begin{array}{l}\text { Reduced } \\
\text { chi-square }\end{array}$ \\
\hline TS1 & & & \\
2 & 20 & 80 & 0.013 \\
6 & 97 & 3 & 0.004 \\
& & & \\
TS2 & & 2 & 0.004 \\
1 & 98 & 11 & 0.034 \\
4 & 89 & 73 & 0.174 \\
8 & 27 & 5 & 0.012 \\
9 & 95 & 21 & 0.034 \\
12 & 79 & & \\
& & & 0.027 \\
Control clipping & 2 & 0.047 \\
i & 98 & 7 & \\
ii & 93 & & 0.099 \\
& & & 0.077 \\
Dry mine waste incubation & 0 & 0.089 \\
i & 100 & 6 & 0.106 \\
ii & 94 & 95 & 0.046 \\
iii & 5 & 23 & 0.029 \\
iv & 77 & & \\
& & 100 & \\
Wet mine waste incubation & 0 & 100 & \\
i & 0 & & \\
ii & 0 & & \\
iii & 0 & & \\
\hline
\end{tabular}



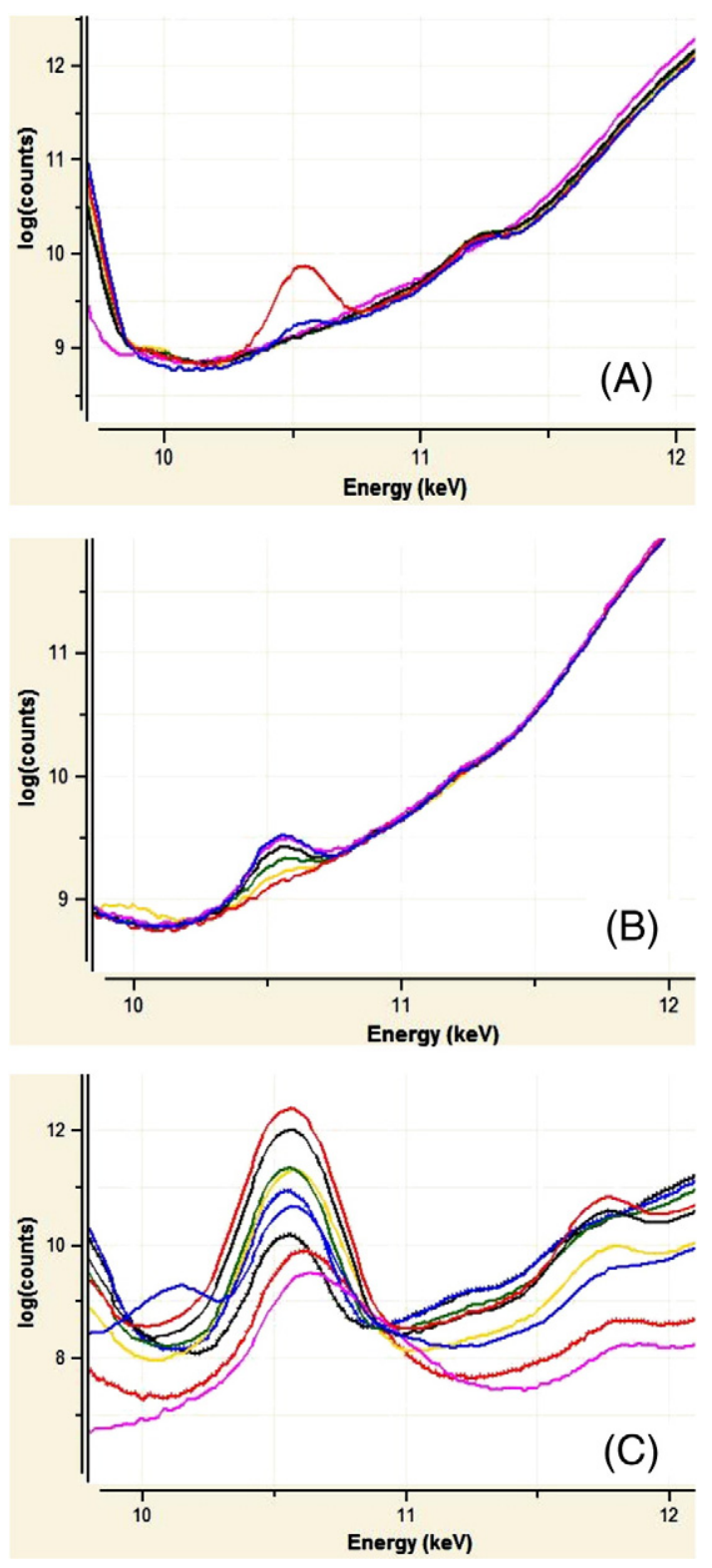

Fig. 5. XRF spectra collected from selected spot locations on (A) the control clipping; (B) the clipping incubated in dry mine waste; and $(C)$ the clipping incubated in wet mine waste showing varying arsenic intensity.

ongoing up to the distal free edge (Johnson et al., 1991). This may explain the extensive presence of arsenic in the ventral layers of TS1 and TS2. The smaller extent of arsenic in the dorsal layers is consistent with arsenic deposition at the root of the growing nail in response to episodic exposures. Incorporation of oral drugs into human nails via both these pathways has been demonstrated (Palmeri et al., 2000). Further, Pounds et al. (1979) identified two peak arsenic concentrations in fingernail clippings following a single ingested dose of arsenic: a minor peak occurring at around 3-4 weeks, and a major peak several weeks later. By scraping away the underside of the nail clippings, Pounds et al. (1979) eliminated the first peak, which they attributed to absorption of arsenic from sweat. However, the ongoing contribution of the nail bed to the formation of the ventral layer was yet to be established (Johnson et al., 1991). It is possible that children absorb arsenic from soil or mine waste via various exposure pathways, primarily soil ingestion (Langley, 2002), prior to it being metabolised and excreted. The dominant oxidised state of arsenic present in mine waste where pyrite and arsenopyrite occur is typically arsenate (Foster et al., 1998; Arčon et al., 2005). Arsenate may be reduced chemically or enzymatically to arsenite in mammalian systems, a critical step enabling methylation of arsenic (Radabaugh and Aposhian, 2000; Radabaugh et al., 2002). Following intake of arsenic, inorganic and methylated metabolites formed in the liver subsequently circulate in the blood (Benramdane et al., 1999), and the arsenic content of nails reflects these concentrations (Hopps, 1977; Koons and Peters, 1994).

XANES analysis in situ identified two distinct arsenic species, neither of which corresponded closely to the standard realgar, arsenite, or arsenate spectra. The arsenic $\mathrm{K}$ absorption edge peak energy of the dominant species at TS1 spots 2 and 9, and TS2 spot 8, is slightly higher than for arsenate, and we denote this higher oxidation state species as $\mathrm{As} \approx \mathrm{V}(-\mathrm{O})$, although further research is required to elucidate the oxidation state, ligand type and coordination environment of this species to explain this shift in the edge position. It is noted that integer oxidation states are valid only for completely ionic compounds and that electron binding energy depends in part on the electronegativity as well as the electron affinity of surrounding atoms, neither of which are integer values (Gerson et al., 1999).

The dominant species at TS1 spots 1 and 6 , and TS2 spots 1, 4, 9, and 12 , has an absorption edge peak energy between those of realgar and arsenite, suggesting that the oxidation state of the arsenic is actually less than that of arsenite. Comparisons between model compound and sample spectra enable empirical identification of arsenic oxidation states, since the arsenic $\mathrm{K}$ absorption edge (corresponding to electron excitation to the lowest unoccupied molecular orbital) shifts to higher energies with increasing oxidation state (Foster et al., 1998; Schwenzer et al., 2001; Smith et al., 2005). Smith et al. (2005) have characterised XANES of various biologic samples to facilitate such comparisons, and report an arsenic $\mathrm{K}$ adsorption edge peak energy of $11,871.7 \mathrm{eV}$ for arsenite and $11,875.3 \mathrm{eV}$ for arsenate. These values are highly comparable to our results (Table 1 ), in particular since our XANES were collected using step-size of $0.5 \mathrm{eV}$. Further, our absorption edge peak energy of $11,870 \mathrm{eV}$ for realgar (As-S) is similar to results obtained by Smith et al. (2005) for arsenic glutathione $\left(\mathrm{As}^{\mathrm{III}}(\mathrm{Glu})_{3}\right)$. Due to the lower electronegativity of sulphur as compared to oxygen, arsenic $\mathrm{K}$ adsorption edge peak energies of sulphur-containing compounds are lower than for arsenite, since core electrons of arsenic atoms are more easily photoionised in As-S than As-O bonds, with increasing methylation reducing the absorption edge peak energies to a lesser extent than As-S binding (Smith et al., 2005). Our low oxidation state arsenic species is similar to compounds incorporating mixed sulphur and methyl coordination with white line energy of $11,870.8 \mathrm{eV}$ reported by Smith et al. (2005), including MMA ${ }^{\mathrm{III}}$. We therefore use the label $\mathrm{As}_{(-\mathrm{S},-\mathrm{CH} 3)}$ to denote this species. Some evidence of arsenic-sulphur coordination, with arsenite comprising the principal species determined by linear least square fitting, was also found by Gault et al. (2008) who applied XANES analysis to whole fingernail clippings of four individuals exposed to arsenic-rich groundwaters.

We detected no evidence of species corresponding to monomethylarsonic acid $\left(\mathrm{MMA}^{\mathrm{V}}\right)$ or dimethylarsinic acid $\left(\mathrm{DMA}^{\mathrm{V}}\right)$, with white line energies of 11,874.1 eV and 11,873.3 eV, respectively, reported by Smith et al. (2005), although we investigated limited spot locations. It is likely that any dimethylarsinous acid (DMA ${ }^{\mathrm{III}}$ ) in the nail would have been oxidised to DMA ${ }^{\mathrm{V}}$ (Gong et al., 2001; Smith et al., 2005). The relative proportions of organic arsenicals detected in blood, urine, hair, toenails and fingernails may reflect varying degrees of reduction of arsenate to arsenite and methylation, as well as species stability (Mandal et al., 2003; Raab and Feldmann, 2005; Fukai et al., 2006; Button et al., 2009). Aqueous extracts from toenail samples $(n=7)$, including two individuals exposed to arsenic through soil (Button et al., 2009), and from fingernails $(n=41)$ of individuals exposed to arsenic-contaminated water (Mandal et al., 2004), similarly indicate a predominance of inorganic arsenite, with some arsenate, and lesser amounts of $D M A^{V}$, $\mathrm{MMA}^{\mathrm{V}}$, and DMA ${ }^{\mathrm{III}}$. Mean extraction rates in these studies of toenails and fingernails were $53 \%$ and $63.2 \%$, respectively (Mandal et al., 2004; Button et al., 2009). 

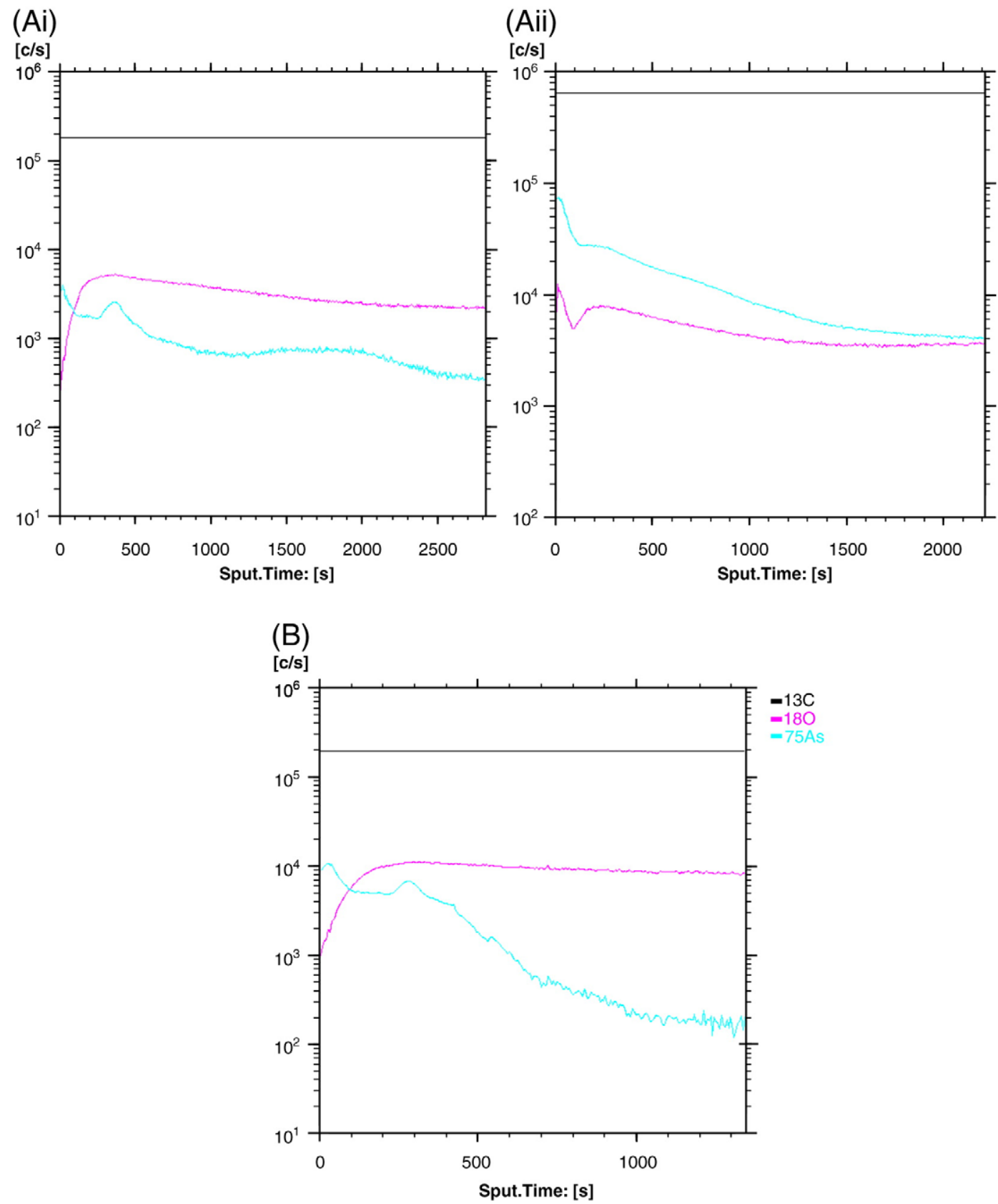

Fig. 6. Depth profiles of the dorsal surfaces of whole clippings using Secondary Ion Mass Spectrometry (SIMS) showing arsenic and oxygen intensities normalised to carbon in replicates from a sample with total arsenic concentration $0.77 \mu \mathrm{g} / \mathrm{g}$ (Ai and ii); and a sample with total arsenic $0.23 \mu \mathrm{g} / \mathrm{g}$ (B).

On the control clipping, only the species denoted $\left.\mathrm{As}_{(-\mathrm{S}} \approx \mathrm{III}-\mathrm{CH} 3\right)$ was detected, whereas mixed speciation was detected on the clipping incubated in dry mine waste. The higher oxidation state species only was detected on the clipping incubated in wet mine waste. It may therefore be speculated that arsenate diffused directly into the clipping incubated in wet mine waste, and that the species denoted $\mathrm{As} \approx \mathrm{V}(-\mathrm{O})$ corresponds to exogenous arsenic, although further research is required to confirm this conjecture. Under dry conditions, less direct diffusion may be expected, since it depends on direct physical contact between soil particles and the biological surface (Rahman et al., 1994). Since it is likely that these clippings were collected from different toes and may reflect different exposure periods due to variation in nail growth rates (Le Gros Clark and Buxton, 1938; Bean, 1953), their arsenic content is not directly comparable. However, some degree of direct diffusion into toenails, as distinct from residual surface contamination, cannot be ruled out when investigating biomarkers of exposure to arsenic in soil or water, particularly since Smith et al. (2008) demonstrated that pentavalent arsenic applied externally to fur and feathers, in either soil or solution, could be reduced to trivalent arsenic and absorbed.

Overall, our findings suggest that arsenic in soil contributes to arsenic uptake by children resident in the study area, further evidenced by the positive correlation between arsenic concentrations in toenail clippings and residential soils. Significantly higher nail arsenic concentrations have been observed in children compared with adults in communities with soil arsenic levels up to $1263 \mu \mathrm{g} / \mathrm{g}$ (Wickre et al., 2004) and $9900 \mu \mathrm{g} / \mathrm{g}$ (Hinwood et al., 2003), although ranges were not reported separately. Our observed toenail arsenic concentrations were similar to those found in adults with arsenic concentrations in drinking water from nondetectable to $137 \mu \mathrm{g} / \mathrm{L}$, which ranged from 0.07 to $2.25 \mu \mathrm{g} / \mathrm{g}$ (Karagas et al., 1996); generally 
much lower than a convenience sample of adults potentially exposed to elevated soil arsenic ( 0.86 to $25.98 \mu \mathrm{g} / \mathrm{g}$ ) while slightly higher than the control group (0.07 to $0.27 \mu \mathrm{g} / \mathrm{g}$ ) (Button et al., 2009); and lower than children exposed to extreme arsenic contamination in water ( $749 \mu \mathrm{g} / \mathrm{L}$ ), which ranged from 2.84 to $7.92 \mu \mathrm{g} / \mathrm{g}$ (Chakraborti et al., 2003). It has been suggested that arsenic exposure may inhibit deoxyribonucleic acid (DNA) repair mechanisms, thus enabling arsenic to act as a cocarcinogen through enhancement of the genotoxic and mutagenic capacity of other compounds (Andrew et al., 2006), but only extreme levels of chronic exposure are typically associated with arsenicosis (Chakraborti et al., 2003).

\section{Conclusions}

Arsenic in soil contributes to arsenic uptake by children living in an area of historical gold mining in Victoria, Australia. XRF mapping of the microdistribution of arsenic in clipping thin sections suggested episodic exposures, and enabled us to relate arsenic incorporation to nail structure and formation. SIMS confirmed arsenic incorporation within clippings, and XANES analysis identified two species: a lower oxidation state species with mixed sulphur and methyl coordination, and a higher oxidation state species. Further research is required to elucidate the oxidation state, degree of methylation and coordination of arsenic species in situ in nail clippings, since they affect the genotoxicity and cytotoxicity of arsenic (Tchounwou et al., 2003). The application of synchrotron-based techniques, including extended X-ray absorption fine structure spectroscopy (EXAFS), has the potential to increase knowledge of arsenic metabolism and excretion in those chronically exposed to arsenic, and differentiate between systemically absorbed and exogenous arsenic. Future epidemiological studies are required to ascertain if adverse health effects are associated with current levels of arsenic exposure in the study area using improved exposure estimates now possible with the analytical techniques described in this paper.

\section{Acknowledgements}

We acknowledge the support of GeoSoilEnviroCARS, which is supported by the National Science Foundation - Earth Sciences (EAR0622171), and the Department of Energy - Geosciences (DE-FG0294ER14466). Use of the Advanced Photon Source was supported by the U. S. Department of Energy, Office of Science, Office of Basic Energy Sciences, under Contract No. DE-AC02-06CH11357. This research was also supported by the Australian Synchrotron Research Program (06/ 07-GSE-02 and 07/08-GSE-01), an Australian Institute of Nuclear Science and Engineering (AINSE) award (AINGRA06051), and a University of Ballarat Postgraduate Award. The participation of ARG in this research was supported under the Australian Research Council's Linkage Project funding scheme (project number LP0562210) which was sponsored by Rio Tinto and the Department of Innovation, Industry and Regional Development, State Government of Victoria. We thank Robert Smith and Stafford McKnight for their assistance with thin section preparation, and the child participants, their families and school communities for their contribution to this research.

\section{References}

Alauddin M, Alauddin ST, Bhattacharjee M, Sultana S, Chowdhury D, Bibi H, et al. Speciation of arsenic metabolite intermediates in human urine by Ion-Exchange Chromatography and Flow Injection Hydride Generation Atomic Absorption Spectrometry. J Environ Sci Health A Toxicol Hazard Subst Environ Eng 2003;38: $115-28$.

Andrew AS, Burgess JL, Meza MM, Demidenko E, Waugh MG, Hamilton JW, et al. Arsenic exposure is associated with decreased DNA repair in vitro and in individuals exposed to drinking water arsenic. Environ Health Perspect 2006;114:1193-8.

Arčon I, van Elteren JT, Glass HJ, Kodre A, Slejkovec Z. EXAFS and XANES study of arsenic in contaminated soil. X-ray Spectrom 2005:34:435-8.

Bean WB. A note on fingernail growth. J Invest Dermatol 1953;20:27-31.
Beane Freeman LE, Dennis LK, Lynch CF, Thorne PS, Just CL. Toenail arsenic content and cutaneous melanoma in Iowa. Am J Epidemiol 2004;160:679-87.

Benramdane L, Accominotti M, Fanton L, Malicier D, Vallon J-J. Arsenic speciation in human organs following fatal arsenic trioxide poisoning - a case report. Clin Chem 1999;45:301-6.

Birks LS, Gilfrich JV, Criss JW. NRLXRF: Cosmic Program \#DOD-00065. Largo MD: US Naval Research Laboratory; 1977.

Buchet JP, Lauwerys R, Roels $\mathrm{H}$. Comparison of the urinary excretion of arsenic metabolites after a single oral dose of sodium arsenite, monomethylarsonate, or dimethylarsinate in man. Int Arch Occup Environ Health 1981;48:71-9.

Button M, Jenkin GRT, Harrington CF, Watts MJ. Human toenails as a biomarker of exposure to elevated environmental arsenic. J Environ Monit 2009;11:610-7, doi: 10.1039/b817097e.

Centeno JA, Tseng C-H, Van der Voet GB, Finkelman RB. Global impacts of geogenic arsenic: a Medical Geology research case. Ambio 2007;36:78-81.

Chakraborti D, Mukherjee SC, Pati S, Sengupta MK, Rahman MM, Chowdhury UK, et al. Arsenic groundwater contamination in Middle Ganga Plain, Bihar, India: a future danger? Environ Health Perspect 2003;111:1194-201.

Concha G, Nermell B, Vahter M. Metabolism of inorganic arsenic in children with chronic high arsenic exposure in Northern Argentina. Environ Health Perspect 1998:106:355-9.

Department of Manufacturing and Industry Development. Arsenic in the Environment: Stage 1 Report. Victoria, Australia: DMID; 1991.

enHealth Council. The National Environmental Health Strategy. Canberra, ACT: Commonwealth of Australia; 1999.

Fahrni CJ. Biological applications of X-ray fluorescence microscopy: exploring the subcellular topography and speciation of transition metals. Curr Opin Chem Biol 2007;11(2):121-7.

Farren L, Shayler S, Ennos AR. The fracture properties and mechanical design of human fingernails. J Exp Biol 2004;207:735-41.

Foster AL, Brown Jr GE, Tingle TN, Parks GA. Quantitative arsenic speciation in mine tailings using X-ray absorption spectroscopy. Am Mineral 1998;83:553-68.

Fukai Y, Hirata M, Ueno M, Ichikawa N, Kobayashi H, Saitoh H, et al. Clinical pharmacokinetic study of arsenic trioxide in an acute Promyelocytic Leukemia (APL) patient: speciation of arsenic metabolites in serum and urine. Biol Pharm Bull 2006;29(5):1022-7.

Garson JC, Baltenneck F, Leroy F, Riekel C, Muller M. Histological structure of human nai as studied by synchrotron X-ray microdiffraction. Cell Mol Biol 2000;46:1025-34.

Gault AG, Rowland HAL, Charnock JM, Wogelius RA, Gomez-Morilla I, Vong S, et al. Arsenic in hair and nails of individuals exposed to arsenic-rich groundwaters in Kandal province, Cambodia. Sci Total Environ 2008;393:168-76.

Gerson AR, Lange AG, Prince KE, Smart RStC. The mechanism of copper activation of sphalerite. Appl Surf Sci 1999;137:207-23.

Gong Z, Lu X, Cullen WR, Le XC. Unstable trivalent arsenic metabolites, monomethylarsonous acid and dimethylarsinous acid. J Anal At Spectrom 2001;16:1409-13.

Hinwood AL, Sim MR, Jolley D, de Klerk N, Bastone EB, Gerostamoulos J, et al. Hair and toenail arsenic concentrations of residents living in areas with high environmental arsenic concentrations. Environ Health Perspect 2003;111:187-93.

Hinwood AL, Sim MR, Jolley D, de Klerk N, Bastone EB, Gerostamoulos J, et al. Exposure to inorganic arsenic in soil increases urinary inorganic arsenic concentrations of residents living in old mining areas. Environ Geochem Health 2004;26:27-36.

Hopps HC. The biological base of using hair and nail for analysis of trace elements. Sc Total Environ 1977; 7:71-87.

Johnson M, Comaish JS, Shuster S. Nail is produced by the normal nail bed: a controversy resolved. Br J Dermatol 1991;125:27-9.

Karagas MR, Morris JS, Weiss JE, Spate V, Baskett C, Greenberg ER. Toenail samples as an indicator of drinking water arsenic exposure. Cancer Epidemiol Biomarkers Prev 1996:5:849-52.

Karagas MR, Tosteson TD, Blum J, Klaue B, Weiss JE, Stannard V, et al. Measurement of low levels of arsenic exposure: a comparison of water and toenail concentrations. Am J Epidemiol 2000;152:84-90.

Kitahara T, Ogawa $\mathrm{H}$. The extraction and characterization of human nail keratin. J Dermatol Sci 1991;2:402-6.

Kitchin KT, Wallace K, Andrewes P. Some chemical properties underlying arsenic's biological activity. In: Chappell WR, Abernathy CO, Calderon RL, Thomas DJ, editors. Arsenic Exposure and Health Effects V. Amsterdam: Elsevier; 2003. p. 345-54.

Kligerman AD, Doerr CL, Tennant AH. Oxidation and methylation status determine the effects of arsenic on the mitotic spindle. Mol Cell Biochem 2005;279:113-21.

Koons RD, Peters CA. Axial distribution of arsenic in individual human hairs by Solid Sampling Graphite Furnace AAS. J. Anal Toxicol 1994;18:36-40.

Kurttio P, Komulainen H, Hakala E, Kahelin H, Pekkanen J. Urinary excretion of arsenic species after exposure to arsenic present in drinking water. Arch Environ Contam Toxicol 1998;34:297-305.

Langley AJ. The soiled environment: bubble, bubble, soil in trouble. Med J Aust 2002;177:599-603.

Le Gros Clark WE, Buxton LHD. Studies in nail growth. Br J Dermatol Syph 1938;50:221-35.

Mandal BK, Ogra Y, Suzuki KT. Identification of dimethylarsinous and monomethylarsonous acids in human urine of the arsenic-affected areas in West Bengal, India. Chem Res Toxicol 2001;14:371-8.

Mandal BK, Ogra Y, Suzuki KT. Speciation of arsenic in human nail and hair from arsenic-affected area by HPLC-inductively coupled argon plasma mass spectrometry. Toxicol Appl Pharmacol 2003;189:73-83.

Mandal BK, Ogra Y, Anzai K, Suzuki KT. Speciation of arsenic in biological samples. Toxicol Appl Pharmacol 2004;198:307-18.

McArthur JM, Ravenscroft P, Safiulla S, Thirlwall MF. Arsenic in groundwater: testing pollution mechanisms for sedimentary aquifers in Bangladesh. Water Resour Res 2001;37:109-17. 
Mork C, Kvernebo K, Asker CL, Salerud EG. Reduced skin capillary density during attacks of erythromelalgia implies arteriovenous shunting as pathogenetic mechanism. J Invest Dermatol 2002;119:949-53.

Newville M. DataViewer Program Version 2.03. GSECARS, University of Chicago, Chicago, IL, 2006, downloaded 29 January 2007, <http://cars9.uchicago.edu/ newville/dataviewer/>.

Nickson RT, McArthur JM, Ravenscroft P, Burgess WG, Ahmed KM. Mechanism of arsenic release to groundwater, Bangladesh and West Bengal. Appl Geochem 2000; $15: 403-13$

Palmeri A, Pichini S, Pacififi R, Zuccaro P, Lopez A. Drugs in nails: physiology, pharmacokinetics and forensic toxicology. Clin Pharmacokinet 2000;38:95-110.

Petrick JS, Ayala-Fierro F, Cullen WR, Carter DE, Aposhian HV. Monomethylarsonous acid $\left(\mathrm{MMA}^{\mathrm{III}}\right)$ is more toxic than arsenite in Chang human hepatocytes. Toxicol Appl Pharmacol 2000;163:203-7.

Pounds CA, Pearson EF, Turner TD. Arsenic in fingernails. J Forensic Sci Soc 1979;19: 165-73.

Raab A, Feldmann J. Arsenic speciation in hair extracts. Anal Bioanal Chem 2005;381: 332-8.

Radabaugh TR, Aposhian HV. Enzymatic reduction of arsenic compounds in mammalian systems: reduction of arsenate to arsenite by human liver arsenate reductase. Chem Res Toxicol 2000;13:26-30.

Radabaugh TR, Sampayo-Reyes A, Zakharyan RA, Aposhian HV. Arsenate reductase II. Purine nucleoside phosphorylase in the presence of dihydrolipoic acid is a route for reduction of arsenate to arsenite in mammalian systems. Chem Res Toxicol 2002;15:692-8.

Rahman MS, Hall LL, Hughes MF. In vitro percutaneous absorption of sodium arsenate in $\mathrm{B}_{6} \mathrm{CF}_{1}$ mice. Toxicol In Vitro 1994;8:441-8.

Ravel B. Athena EXAFS Data Processing Software Release 0.8.050. University of Chicago, Chicago, IL, 2001-2006, downloaded 29 January 2007, <http://cars9.uchicago.edu/ ravel/software/exafs/>.

Ravel B. Athena User's Guide Document version 1.3 for Athena version 0.8.54. University of Chicago, Chicago, IL, 2007, downloaded 7 May 2009, <http://cars9. uchicago.edu/ ravel/software/exafs/>.

Rivers M. MCA-IDL Multichannel Analyzer Program, University of Chicago, Chicago, IL, 1997, <http://cars9.uchicago.edu/software/idl/mcaDisplay.html>

Rodushkin I, Axelsson MD. Application of double focusing sector field ICP-MS for multielemental characterization of human hair and nails. Part II. A study of the inhabitants of northern Sweden. Sci Total Environ 2000;262:21-36.

Rodushkin I, Axelsson MD. Application of double focusing sector field ICP-MS for multielemental characterization of human hair and nails. Part III. Direct analysis by laser ablation. Sci Total Environ 2003;305:23-39.
Samman PD. The Nails in Disease. 3rd ed. London: William Heinemann Medical Books; 1978. p. 1-17.

Schwenzer SP, Tommaseo CE, Kersten M, Kirnbauer T. Speciation and oxidation kinetics of arsenic in the thermal springs of Wiesbaden spa, Germany. Fresenius J Anal Chem 2001;371:927-33.

Slotnick MJ, Nriagu JO. Validity of human nails as a biomarker of arsenic and selenium exposure: a review. Environ Res 2006;102:125-39.

Slotnick MJ, Meliker JR, AvRuskin GA, Ghosh D, Nriagu JO. Toenails as a biomarker of inorganic arsenic intake from drinking water and foods. J Toxicol Environ Health A 2007;70:148-58.

Smith E, Smith J, Smith L, Biswas T, Correll R, Naidu R. Arsenic in Australian environment: an overview. J Environ Sci Health A Toxicol Hazard Subst Environ Eng 2003;A38:223-39.

Smith PG, Koch I, Gordon RA, Mandoli DF, Chapman BD, Reimer KJ. X-ray absorption near-edge structure analysis of arsenic species for application to biologica environmental samples. Environ Sci Technol 2005;39:248-54.

Smith PG, Koch I, Reimer KJ. An investigation of arsenic compounds in fur and feathers using X-ray absorption spectroscopy speciation and imaging. Sci Total Environ 2008;390(1):198-204.

Sukumar A. Human nails as a biomarker of element exposure. Rev Environ Contam Toxicol 2006; 185:141-77.

Sultan K. Distribution of metals and arsenic in soils of Central Victoria (CreswickBallarat), Australia. Arch Environ Contam Toxicol 2007;52:339-46.

Sultan K, Dowling K. Arsenic and major cation hydrochemistry of the Central Victorian (Australia) surface waters. J Environ Sci 2006a;18:184-92.

Sultan K, Dowling K. Seasonal changes in arsenic concentrations and hydrogeochemistry of Canadian Creek, Ballarat (Victoria, Australia). Water Air Soil Pollu 2006b;169:355-74.

Sutton SR, Bertsch PM, Newville M, Rivers M, Lanzirotti A, Eng P. Microfluorescence and microtomography analyses of heterogeneous earth and environmental materials. In: Fenter PA, Rivers ML, Sturchio NC, Sutton SR, editors. Reviews in Mineralogy \& Geochemistry: Applications of Synchrotron Radiation in Low-Temperature Geochemistry \& Environmental Science. Chantilly, VA, vol. 49. Mineral Soc Am; 2002. p. 429-83.

Takagi Y, Matsuda S, Imai S, Ohmori Y, Masuda T, Vinson JA et al. Survey of trace elements in human nails: an international comparison. Bull Environ Contam Toxicol 1988;41:690-5

Tchounwou PB, Patlolla AK, Centeno JA. Carcinogenic and systemic health effects associated with arsenic exposure - a critical review Toxicol Pathol 2003:31:575-88.

Wickre JB, Folt CL, Sturup S, Karagas MR. Environmental exposure and fingernail analysis of arsenic and mercury in children and adults in a Nicaraguan gold mining community. Arch Environ Health 2004;59:400-9. 